\title{
Quantitative effects of changes in agricultural irrigation on potential evaporation
}

\author{
Congying $\operatorname{Han}^{1}$, Baozhong Zhang ${ }^{2}$, and Songjun $\mathrm{Han}^{3}$ \\ ${ }^{1}$ State Key Laboratory of Simulation and Regulation of Water Cycle in River Basin \\ ${ }^{2}$ China Agricultural University \\ ${ }^{3}$ China Institute of Water Resources and Hydropower Research
}

August 21, 2020

\begin{abstract}
Evaporation is the key to the basin's water cycle. Agricultural irrigation has resulted in a significant variation of regional potential evaporation $\left(\mathrm{E}_{\mathrm{pen}}\right)$. The spatiotemporal variation of $\mathrm{E}_{\mathrm{pen}}$ and the influencing factors in the natural, agricultural, and desert areas in different developmental stages of irrigation in the Heihe River Basin (HRB) from 1970 to 2017 are comparatively analyzed in this study. This work focused on the correction effect of irrigation on the variation of $\mathrm{E}_{\text {pen }}$. The agricultural water consumption in HRB significantly varied around 1998 due to the agricultural development and water policy. Under the influence of irrigation, the annual variation of $\mathrm{E}_{\text {pen }}$ in the agricultural, natural, and desert areas was significantly different. From 1970 to 1998 , the annual trend slope of $\mathrm{E}_{\text {pen }}$ in the natural area only reduced by $1 \mathrm{~mm}$ decade $\mathrm{e}^{-1}$, while that in the agricultural area significantly decreased by $39 \mathrm{~mm}$ decade $^{-1}$. After the implementation of water-saving irrigation, the $\mathrm{E}_{\text {pen }}$ in the natural and agricultural areas increased by 11 and $54 \mathrm{~mm} \mathrm{decade}^{-1}$, respectively, from 1998 to 2017 . In contrast with the natural and agricultural areas, $E_{\text {pen }}$ in the desert area decreased by $80 \mathrm{~mm} \mathrm{decade}^{-1}$ from 1970 to 1998 and continuously decreased by 41 $\mathrm{mm}$ decade $^{-1}$ from 1998 to 2017 . However, the regulatory effect of irrigation on $\mathrm{E}_{\mathrm{pen}}$ in the desert area started to manifest due to the expansion of the cultivated land area in the desert area from 2010 to 2017. Irrigation has a significant regulatory effect on the variation of $\mathrm{E}_{\mathrm{pen}}$ in $\mathrm{HRB}$. The regulatory effect is mainly reflected on the aerodynamic term ( $\mathrm{E}_{\text {aero }}$ ). The analytical results of the main meteorological factors affecting Epen in different regions indicated that the main meteorological factors influencing the variation of $E_{\text {pen }}$ in each region are the wind speed $2 \mathrm{~m}$ above the surface $\left(\mathrm{U}_{2}\right)$ and the water vapor pressure difference (VPD).
\end{abstract}

\section{Hosted file}

Manuscript.pdf available at https://authorea.com/users/352843/articles/476924-quantitativeeffects-of-changes-in-agricultural-irrigation-on-potential-evaporation 


\section{Figure captions}

560 Fig. 1 Spatial location and characteristics of the HRB.

Fig. 2 Annual runoff at different hydrological stations and water diversion in the upstream of the agricultural area in HRB.

Fig. 3 Distribution of trend slopes per decade of $E_{p e n}, E_{\text {rad }}$, and $E_{a e r o}$ in the different stations in the HRB (1970-2017).

565 Fig. 4 Annual variations of the averaged $E_{p e n}, E_{r a d}$, and $E_{\text {aero }}$ in different regions in the HRB.

567 Fig. 5 Relationship between the variations of potential and actual evaporation in the HRB

569 Fig. 6 Fitting of the $E_{p e n}$ variation calculated by the regression and trend analytical methods in the HRB. 
571 Table captions

572 Table 1. Meteorological conditions and regional characteristics of the different regions in HRB

573 Table 2. Location of the meteorological stations and the percentage of cultivated land area within $4 \mathrm{~km}$ of the stations in HRB

574 Table 3. Trend slopes per decade of $E_{p e n}, E_{r a d}$, and $E_{a e m}$ in different regions in the HRB (1970-2017).

575 Table 4. Trend slopes per decade of the meteorological factors in different regions in the HRB (1970-2017).

576 Table 5. Trend slopes per decade of $E_{p e n}, E_{\text {rad, }}$, and $E_{\text {aer }}$ at different stations in the HRB (1970-2017).

577 Table 6. Contributions of the meteorological factors to the variation of $E_{p e n}$ in different regions in the HRB 